\title{
SELEÇÃO DE PROGÊNIES E GENITORES DE PESSEGUEIRO COM BASE NAS CARACTERÍSTICAS DOS FRUTOS ${ }^{1}$
}

\author{
AMÉRICO WAGNER JÚNIOR², CLAUDIO HORST BRUCKNER ${ }^{3}$, CELIA MARÍA CANTÍN ${ }^{4}$, \\ MARÍA ANGELES MORENO SÁNCHEZ ${ }^{3}$, CARLOS EDUARDO MAGALHÃES DOS SANTOS
}

RESUMO - Melhorar a qualidade do fruto é um dos principais objetivos dos programas de melhoramento genético do pessegueiro, tendo relação direta com as preferências de mercado e do consumidor. Quando se fala em qualidade, busca-se obter plantas produtivas, com frutos grandes e firmes, com ótimos sabor e coloração. Porém, o pêssego produzido no Brasil ainda deixa a desejar, principalmente em firmeza, quando comparado aos padrões internacionais. Os objetivos deste trabalho foram avaliar, selecionar e indicar genótipos que apresentem frutos de boa qualidade e com polpa não fundente, para utilização futura como genitor masculino no programa de melhoramento de pessegueiro da Universidade Federal de Viçosa. Os trabalhos foram desenvolvidos na Estação Experimental de Aula Dei (CSIC), Zaragoza - Espanha, durante o período de maio a agosto de 2006, sendo analisados cerca de 687 indivíduos, pertencentes a 17 populações de pessegueiro. Com base nos resultados obtidos, pólen de 'Crown Princess' e dos seedlings VADAC 0027, VADAC 0052, VADAC 0063 e VADAC0065 podem ser recomendados para utilização como genitores no programa de melhoramento do pessegueiro da UFV, visando a obter frutos de boa qualidade e com textura não fundente.

Termos para indexação: Prunus persica, melhoramento do pessegueiro, textura de frutos.

\section{HIGH FRUIT QUALITY PEACH TREE PROGENIES AND PARENTS SELECTION}

\begin{abstract}
Good fruit quality is one of the most important objectives in peach breeding, it has a direct relationship with the market and consumer preferences. With regard to quality, it means to obtain productive plants, with large and firm fruits, good flavor and attractive color. However, Brazilian peach still does not present good characteristics, mainly regarding firmness, when compared with the international peach patterns. The aim of this study was to evaluate, to select and to indicate some peach genotypes that produce fruit with good quality and non-melting flesh, for future use as male parent in the Peach Breeding Program of Universidade Federal de Viçosa. The studies were carried out at the Experimental Station of Aula Dei (CSIC), Zaragoza - Spain, during the period of May to August in 2006. About 687 seedlings, from 17 peach populations [Prunus persica (L.) Batsch], were evaluated. Based on the obtained results, pollen from 'Crown Princess' and from seedlings VADAC 0027, VADAC 0052, VADAC 0063 and VADAC0065 could be recommended as parent in the Peach Breeding Program of UFV, aiming to obtain non-melting flesh fruits, with good quality traits.
\end{abstract}

Index terms: Prunus persica, peach breeding, fruit texture.

'(Trabalho 057-10). Recebido em: 25-02-2010. Aceito para publicação em: 28-09-2010.

${ }^{2}$ Doutor Professor. Universidade Tecnológica Federal do Paraná - Campus Dois Vizinhos, Dois Vizinhos - PR. e-mail: americowagner@utfpr.edu.br

33Doutor Professor. Universidade Federal de Viçosa, Viçosa - MG. e-mail: bruckner@ufv.br. carlos.magalhaes@ufv.br

${ }^{4} \mathrm{PhD}$. Pesquisadora. Estação Experimental de Aula Dei (CSIC), Zaragoza - Espanha. e-mail: mmoreno@eead.csic.es, celia@eead.csic.es 


\section{INTRODUÇÃO}

Os programas de melhoramento do pessegueiro desenvolvidos no Brasil são responsáveis por cerca de $90 \%$ das cultivares plantadas no País, sendo que os primeiros programas desenvolvidos no Brasil foram criados pelo Instituto Agronômico, em Campinas (SP), e pela Embrapa - Centro de Pesquisa Agropecuário de Clima Temperado, em Pelotas (RS), com início em 1947 e 1953, respectivamente (BARBOSA et al., 1999). Estes programas são até hoje considerados de maior importância nacional, pois trouxeram as maiores contribuições ao cultivo desta espécie no País.

A contribuição da pesquisa até o presente foi da mais alta relevância, pois, além de modernizar as técnicas de cultivo, estendeu de 20 para cerca de 100 dias a época de colheita, através da criação de diversas cultivares, principalmente de maturação precoce (RASEIRA et al., 1992). Contudo, o pêssego aqui produzido, embora de ótimo sabor, não raro deixa a desejar em tamanho, aparência, firmeza e conservação, quando comparado aos padrões internacionais.

Nas cultivares para consumo in natura plantadas no Sudeste, um problema que se destaca é a falta de firmeza da polpa e, consequentemente, menor resistência ao transporte e vida de prateleira. O problema da falta de firmeza da polpa é especialmente acentuado nos pêssegos doces e de polpa branca, preferidos pelo mercado brasileiro (EMBRAPACNPFT, 1984).

Atualmente, existe a tendência de se desenvolverem cultivares de pêssegos com textura de polpa não fundente para consumo in natura, especialmente aquelas de maturação precoce (RASEIRA; NAKASU, 2000; GIOVANNINI et al., 2006).

Os pêssegos com polpa não fundente são mais firmes e têm, consequentemente, maior resistência ao transporte e manuseio. Num levantamento realizado por Byrne e Bacon (1999), pode-se observar que o programa desenvolvido pelo Centro de Pesquisa Agropecuário de Clima Temperado, em Pelotas, lançou desde sua criação, em 1953, até 1999, cerca de 30 cultivares, sendo que $55 \%$ dos germoplasmas utilizados foram baseados em cultivares com textura não fundente. Já do programa paulista, desenvolvido pelo Instituto Agronômico de Campinas, 45\% dos germoplasmas utilizados para a criação de novas cultivares tinham como característica polpa não fundente.

O germoplasma nativo da Espanha é caracterizado por produzir frutos com ótima qualidade e com polpa não fundente, representando $60 \%$ do total existente (BADENES et al., 1998). Na Estação Ex- perimental de Aula Dei (CSIC), em Zaragoza, foram feitos estudos com o germoplasma de pessegueiros nativos da Espanha, comparando-os com cultivares estrangeiras,verificando-se que as variedades autóctones tinham, em muitos casos, melhor qualidade, sabor e apresentação do que as estrangeiras. Essa coleção, rica em tipos autóctones, pode representar grande interesse para os melhoristas (BOUHADIDA et al., 2007), como dos programas de melhoramento do Brasil.

A característica da textura da polpa não fundente é controlada por um gene com dois alelos recessivos $(\mathrm{m} / \mathrm{m})$ (GIOVANNINI et al., 2006). Neste sentido, uma vez selecionados genótipos com frutos de polpa firme e de alta qualidade, seria possível incorporá-los ao programa de melhoramento da Universidade Federal de Viçosa, através de hibridações e retrocruzamentos com cultivares adaptadas às condições edafoclimáticas da região Sudeste.

A introdução destes genótipos no mencionado programa de melhoramento poderá trazer perspectivas positivas na produção de frutos com excelente qualidade para o mercado brasileiro, podendo incentivar o cultivo de pessegueiro nas zonas aptas para a cultura.

Os objetivos deste trabalho foram avaliar e selecionar genótipos que apresentem frutos de boa qualidade e com textura não fundente, para utilização futura como genitor masculino no programa de melhoramento de pessegueiro da Universidade Federal de Viçosa.

\section{MATERIAL E MÉTODOS}

Os trabalhos foram desenvolvidos na Estação Experimental de Aula Dei, Consejo Superior de Investigaciones Científicas (EEAD-CSIC), Zaragoza Espanha, durante o período de maio a agosto de 2006.

Foram analisados 687 indivíduos, pertencentes a 17 populações de pessegueiro [Prunus persica (L.) Batsch]. O número de indivíduos em cada população variou entre sete e noventa e três plantas (Tabela 1).

As populações foram plantadas em espaçamento de 4,0 $\mathrm{m}$ x 2,5 m, identificadas pelo ano e número do cruzamento. Práticas culturais de rotina foram empregadas durante o período do experimento, exceção para o raleio dos frutos. As plantas do experimento estavam em solo calcário, com $33 \%$ de carbonato de cálcio total, $8 \%$ de $\mathrm{CaO}, \mathrm{pH}$ em água 8,4 e textura francoargilosa.

De cada genótipo coletaram-se todos os frutos que apresentavam o máximo desenvolvimento e a coloração de fundo da epiderme, passando de verde 
para verde-amarelada ou branco-creme (CANTILLANO; SACHS, 1984).

Depois de coletados, os frutos foram levados para laboratório de análise de frutos, onde foram caracterizados de acordo com sua tipologia (variedade botânica) (Tabela 1) e pesados para a obtenção da produção por planta $(\mathrm{kg})$, com auxílio de balança digital. Através do quociente entre a produção por planta e o número de frutos colhidos, obteve-se a massa média do fruto $(\mathrm{g})$.

A tipologia de cada genótipo foi caracterizada de acordo com a variedade botânica apresentada, podendo ser pêssego, nectarina ou peento, sendo este último também conhecido como pêssego-chato.

Após esta avaliação, foram separadas amostras constituídas por 15 frutos, sendo posteriormente avaliadas as características como coloração da epiderme ( $\%$ de vermelho da casca); textura (fundente e não fundente); firmeza de polpa (libras); diâmetros sutural, equatorial e polar $(\mathrm{mm})$; relação diâmetro polar/diâmetro sutural; teor de sólidos solúveis totais dos frutos ( $\left.{ }^{\circ} \mathrm{Brix}\right)$; $\mathrm{pH}$; acidez total titulável (expressa em equivalente grama de ácido málico por $100 \mathrm{~g}$ de peso fresco); relação entre teor de sólidos solúveis totais da polpa e acidez total titulável.

A coloração da epiderme foi avaliada através de notas, variando de 0 a $100 \%$ de vermelho na epiderme. A textura foi avaliada manualmente de forma subjetiva, realizando-se pequena compressão com o polegar na polpa dos frutos, sendo considerados não fundentes aqueles que não mantiveram aprofundamento da polpa após compressão manual. A firmeza foi determinada em faces opostas na região equatorial de cada fruta, realizada em 5 frutas por planta, após a remoção da epiderme, através de penetrômetro manual Effe-Gi, modelo FT-011, ponteira de $8 \mathrm{~mm}$ de diâmetro, colocado em suporte metálico adaptado. Utilizou-se paquímetro digital, marca Mitutoyo DL10, para as avaliações dos diâmetros sutural (distância máxima transversal do fruto, desde a sutura até a parte oposta), equatorial (distância máxima transversal do fruto, medida perpendicularmente à zona da sutura, ou seja, a distância entre as duas partes centrais das duas faces do fruto) e polar (distância do pedúnculo até o ápice) (mm) (CAILLAVET; SOUTY, 1950). O teor de sólidos solúveis totais dos frutos foi analisado no suco retirado manualmente das faces opostas da região equatorial de cada fruto, por meio de refratômetro digital ATAGO (Palete PR-101).

Para a análise da acidez e $\mathrm{pH}$, separaram-se amostras de polpa de 10 frutos, sem epiderme, trituradas em batedeira mix para frutas. Em seguida, retiraram-se $10 \mathrm{~mL}$ deste suco e acrescentaram-se $90 \mathrm{~mL}$ de água destilada. A partir desta solução, avaliou-se o $\mathrm{pH}$, com auxílio do $\mathrm{pH}$-metro Cristol Microph 2001. Posteriormente, para a determinação da acidez, a solução foi titulada com $\mathrm{NaOH} 0,1 \mathrm{~N}$ até atingir valor de $\mathrm{pH} 8,1$.

Os dados foram submetidos à análise de variância, utilizando-se do delineamento experimental completamente casualizado, sendo cada planta considerada como uma repetição, e cada população como tratamento. As médias foram comparadas pelo teste de Tukey $(p \leq 0,05)$. A distribuição observada dos indivíduos apresentando textura fundente e não fundente, de cada população, foi submetida ao teste de qui-quadrado $\left(\chi^{2}\right)$ para verificar se houve semelhança com a proporção esperada. Todos os dados e análises correspondentes foram efetuados por meio do programa computacional Genes (CRUZ, 2001).

Como critério de seleção, foi adotada a escolha de $20 \%$ das populações avaliadas que apresentaram a maior frequência de superioridade nas características avaliadas e que tiveram porcentagem de indivíduos com polpa não fundente acima de $50 \%$. Com base nestas informações, foram recomendados os genitores com polpa não fundente, envolvidos nas populações selecionadas, para introdução no programa da UFV como genitor masculino em futuras hibridações.

Dentro das populações escolhidas, também foram indicados para seleção e introdução no programa de melhoramento genético de pessegueiro da UFV os $20 \%$ de indivíduos com maiores notas no conjunto das variáveis: produção, número de frutos, massa dos frutos, firmeza e porcentagem de vermelho maior que a média da população, além de textura não fundente, precocidade, relação entre sólidos solúveis e acidez titulável maior que 25 e relação diâmetro polar/diâmetro sutural (DP/DS) próximo a 1,0 .

\section{RESULTADOS E DISCUSSÃO}

Pela análise de variância univariada, houve diferenças significativas entre as populações em todas as variáveis analisadas (Tabela 2).

Comparando-se os resultados de produção por planta entre as populações, pode-se verificar que as maiores médias foram obtidas nas populações VADAC $0049(23,1 \mathrm{~kg})$ e VADAC $0052(17,8 \mathrm{~kg})$.

É importante ressaltar que foram avaliadas plantas implantadas no inverno de 2001-2002, compreendendo o terceiro ano de produção, quando as médias de produção por planta em cada população ainda são relativamente baixas. A partir do quarto ou quinto ano de produção, as plantas de pessegueiro podem produzir entre 40 e $50 \mathrm{~kg}$, dependendo da 
cultivar (BIASI et al., 2004).

As populações VADAC 0062 e VADAC 0055 produziram as maiores médias de número de frutos por planta, com 138 e 120 frutos por planta, respectivamente. Acredita-se que estes valores possam ter relação com a maior capacidade de florescimento e frutificação efetiva, sugerindo-se sua avaliação no próximo ciclo de desenvolvimento.

A massa dos frutos variou de 108 a $246 \mathrm{~g}$, sendo maior nas populações VADAC 0036 (246 g), VADAC 0049 (225 g), VADAC 0065 (221 g), VADAC 0027 (218 g), VADAC 0052 (195 g), VADAC 0063 (194 g), VADAC 0053 (192 g), VADAC 0050 (189), VADAC 0201 (178 g) e VADAC 0051 (175 g). De acordo com a classificação de Biasi et al. (2004), as populações analisadas podem ser classificadas como produtoras de frutos grandes (120 $-150 \mathrm{~g}$ ) e muito grandes ( $>150 \mathrm{~g})$, exceção apenas para a população VADAC 0055 que, de acordo com seus resultados, foi classificada como produtora de frutos médios (70 a $120 \mathrm{~g}$ ).

Através destes resultados, pode-se observar que nem sempre plantas com maior número de frutos e/ou com frutos de maior massa apresentam maior produção $\left(\mathrm{kg}\right.$ planta $\left.^{-1}\right)$, sendo importante que haja equilíbrio entre estas variáveis para que se obtenha boa produtividade, com frutos de qualidade.

As populações VADAC 0065, VADAC 0063, VADAC 0027, VADAC 0055, VADAC 0048, VADAC 9708 e VADAC 0201 apresentaram os maiores teores de sólidos solúveis totais, com médias de 13,$7 ; 13,4 ; 13,4 ; 11,5 ; 11,5 ; 11,3$ e 11,2 ${ }^{\circ}$ Brix, respectivamente.

Os dois menores teores de sólidos solúveis dos frutos, mesmo não diferindo de algumas populações, foram obtidos com VADAC 0062 e VADAC 0050. Este baixo teor de sólidos solúveis pode estar relacionado com a época de maturação dos mesmos, uma vez que $80 \%$ e $66,67 \%$ dos genótipos destas populações (VADAC 0062 e VADAC 0050, respectivamente) tiveram seus frutos colhidos durante o período de maio a junho (Tabela 3). Resultados semelhantes foram obtidos por Frecon et al. (2002), sendo o menor teor de sólidos solúveis em frutos de maturação mais precoce. Segundo Souza et al. (1998; 2000), a produção de frutos precoces com alto teor de sólidos solúveis é um dos grandes obstáculos no melhoramento do pessegueiro.

De acordo com Clareton (2000), para que o pêssego tenha boa qualidade, é necessário que tenha teor de sólidos solúveis acima de $11^{\circ} \mathrm{Brix}$, sendo que os teores abaixo de $10^{\circ}$ Brix, geralmente, não são aceitos pelos consumidores. No presente estudo, dentre as 17 populações analisadas, 9 apresentaram teor de sólidos solúveis totais dos frutos superior a $11^{\circ}$ Brix (Tabela 2).

Com relação ao $\mathrm{pH}$ dos frutos, verificou-se que as populações VADAC 9711, VADAC 0049, VADAC 0050 e VADAC 0027, VADAC 0051, VADAC 0063 , VADAC 0201, VADAC 0065, VADAC 0045, VADAC 0036, VADAC 9708, VADAC 0053 e VADAC 0052 apresentaram os maiores valores, variando entre 3,46 e 3,20. Já a população VADAC 0055 apresentou o menor valor de $\mathrm{pH}(2,98)$.

Para Dirlewanger et al. (1999), frutos de pessegueiro classificados como não ácidos apresentam, quando maduros, valores de $\mathrm{pH}$ superiores a 4,0. Considerando-se este critério, podem-se classificar todas as populações analisadas como de frutos ácidos. Porém, é importante ressaltar que estes frutos foram analisados após a colheita, antes de completar a maturação plena, podendo esta acidez diminuir quando o fruto atingir a plena maturação.

Observou-se que as populações VADAC 9708, VADAC 9711, VADAC 0050, VADAC 0049, VADAC 0051 e VADAC 0027 apresentaram maior acidez em seus frutos. Por outro lado, a população VADAC 0048 apresentou frutos com menor acidez, obtendo-se valor de $0,52 \mathrm{~g}$ de ácido málico/100 mL.

Um bom sabor é conceitualmente complicado de ser definido e consequentemente difícil de ser selecionado. Contudo, os principais fatores que determinam o sabor do fruto são o teor de sólidos solúveis e a acidez (SOUZA et al., 2000). Desta forma, a relação entre sólidos solúveis e acidez titulável é um dos melhores parâmetros para avaliar esta característica (CHITARRA; CHITARRA, 2006).

Leonard et al. (1953) consideraram que frutos de pessegueiro com índices de maturação acima de 25 e acidez abaixo de 0,5 gramas de ácido málico por $100 \mathrm{~mL}$ de suco apresentam excelente sabor.

De acordo com Trevisan (2003), cultivares de pessegueiro com sabor mais doce apresentam índices de maturação acima de 35 , e no caso de frutos mais ácidos, este índice pode variar entre 15 e 25 .

Considerando-se os índices de maturação obtidos, verificou-se que a população VADAC 0048 apresentou relação sólidos solúveis/acidez mais elevada $(23,2)$, em decorrência do menor teor de acidez, enquanto, entre as demais populações, este índice variou entre 11,8 e 20,2. Porém, a VADAC 0048 foi estatisticamente semelhante às populações VADAC 0055, VADAC 0063, VADAC 0004, VADAC 0027 e VADAC 0036. Pelos valores da relação entre o teor dos sólidos solúveis e acidez titulável obtidos no presente trabalho, observou-se que, em todas as populações, os frutos produzidos apresentaram sabor com maior acidez. 
Através dos resultados obtidos nos diâmetros analisados, verificou-se que a população VADAC 0036 apresentou frutos com os maiores diâmetros polar, sutural e equatorial. Entretanto, esta população assemelhou-se estatisticamente às populações VADAC 0027, VADAC 0065 e VADAC 0049 no caso do diâmetro polar e, com VADAC 0049, VADAC 0065, VADAC 0052, VADAC 0027, VADAC 0053, VADAC 0063 e VADAC 0050, para diâmetro sutural, além da VADAC 0049, VADAC 0065, VADAC 0052, VADAC 0027, VADAC 0053 e VADAC 0050, em relação ao diâmetro equatorial.

Segundo Albuquerque et al. (2000), entre as cultivares brasileiras, existe a predominância de frutos globosos-oblongos com ligeiro ápice (relação DP/DS maior que 1,0). Porém, para melhor manuseio, seria interessante a obtenção de frutos arredondados e sem ápice, com relação DP/DS próximo a 1,0. Considerando-se este valor, pode-se verificar que todas as populações analisadas apresentaram frutos com DP/DS igual ou muito próximo a 1,0.

O diâmetro equatorial normalmente é utilizado para separar e classificar os frutos segundo um padrão de qualidade. Esta classificação é muito importante para determinar a categoria do produto, facilitando a comercialização. Com base na classificação internacional (KADER;MITCHELL, 1989), a maioria das populações (VADAC 0049, VADAC 0050, VADAC 0053, VADAC 0036, VADAC 0201, VADAC 0027, VADAC 0065, VADAC 0063, VADAC 0051 e VADAC 0052) enquadrou-se na categoria $\mathrm{AA}$, com frutos apresentando diâmetro equatorial entre 74 e $81 \mathrm{~mm}$. Os frutos das populações VADAC 0004, VADAC 0048, VADAC 9708, VADAC 9711 e VADAC 0062, com diâmetro variando de 68 a 74 $\mathrm{mm}$, foram classificados na categoria A. E por último, as populações VADAC 0045 e VADAC 0055, que produziram frutos com calibre de $62-68 \mathrm{~mm}$, foram selecionados para a categoria $\mathrm{B}$.

De acordo com a Tabela 2, observou-se que as populações VADAC 0027, VADAC 9708, VADAC 0004, VADAC 9711 e VADAC 0048 apresentaram as maiores médias de firmeza da polpa dos frutos. Porém, considerando-se a classificação descrita por Watada et al. (1976), todas as populações analisadas apresentaram frutos considerados firmes $(3-10$ libras).

Considerando-se a porcentagem de indivíduos com polpa não fundente, pode-se observar, na TABELA 4, que as populações VADAC 0004, VADAC 0027, VADAC 0048,VADAC 0050, VADAC 0055 e VADAC 0063 foram as que tiveram números iguais ou acima de $50 \%$.

Pode-se verificar que somente 4 das 17 populações analisadas (VADAC 0004, VADAC 0048, VADAC 0201 e VADAC 0051) apresentaram diferenças significativas entre a proporção de indivíduos esperados com a proporção de indivíduos observados. No caso das populações VADAC 0201 e VADAC 0051, seriam esperados 100\% de indivíduos com polpa não fundente, já que ambos os genitores têm textura de polpa não fundente; no entanto, obteve-se segregação quanto à fundência.

Esta diferença entre a distribuição esperada e a observada para a textura do fruto nestas populações e nas outras duas que apresentaram qui-quadrado significativo, pode estar relacionada com a metodologia de análise realizada, sendo de forma subjetiva. Com isso, para maior confiabilidade e comprovação dos resultados obtidos, sugere-se a realização de novas avaliações por meio de testes enzimáticos (endopoligalacturonase e exo-poligalacturonases).

As populações VADAC 0004, VADAC 0048, VADAC 9711, VADAC 9708 e VADAC 0027 apresentaram maiores porcentagens de coloração vermelha na epiderme de seus frutos. Com exceção desta última, as demais populações citadas apresentaram valores iguais ou acima de $90 \%$ de vermelho na epiderme dos frutos de pessegueiro.

Estes resultados são importantes, pois existe normalmente, no mercado in natura, maior valorização de frutos com epiderme mais avermelhada (ALBUQUERQUE et al., 2000). Entretanto, frutos com epiderme totalmente amarela ainda são bem aceitos, se o tamanho, forma e sabor do pêssego forem bons (RASEIRA; NAKASU, 2006).

Baseando-se nos critérios adotados $(20 \%$ de indivíduos com maiores notas no conjunto das variáveis analisadas), foram selecionadas as populações VADAC 0027, VADAC 0050, VADAC 0063 e VADAC 0065. Dos genitores utilizados nestas populações selecionadas, o 'Vênus', 'Big Top' e 'Mercil' apresentam características de textura fundente, e o pessegueiro de polpa amarela 'Crown Princess' (GIOVANNINI et al., 2006), com polpa não fundente.

Com isso, recomenda-se a incorporação dentro do programa de melhoramento genético de pessegueiro da Universidade Federal de Viçosa, de pólen do pessegueiro de polpa amarela 'Crown Princess', visando a obter progênies com polpa não fundente e com frutos de qualidade.

Baseando-se na segregação obtida, pode-se verificar, na Tabela 4, que os genitores 'VAC-9513', 'VAC-9514', 'VAC-9515' e 'VAC-9516' (Tabela 1), provavelmente, possuem textura não fundente já que ao cruzarem com a cultivar fundente 'Red Top' e 'Mercil' gerará progênie com proporção de 
1:1 para característica não fundente:fundente. Assim, estes genitores podem ser recomendados como genitores masculinos para obtenção de progênies não fundentes. Porém, os demais genitores podem ser incorporados no programa da UFV quando o objetivo for obter frutos com boa qualidade, sem levar em consideração a textura da polpa, visto que possuem genes que determinam boas características agronômicas que poderão ser transmitidas à descendência.
Pelos critérios de seleção adotados, dentro da população VADAC 0027 , foram selecionados os genótipos: $4 ; 11 ; 33 ; 43 ; 47 ; 53 ; 56 ; 58 ; 63 ; 66 ; 71$ e 74. Na população VADAC 0050 , selecionaram-se os genótipos F5-2, F5-5, F5-18, F6-3, F6-10, F6-15, F6-19, F6-20, F6-23, F6-26, F6-30, F6-37 e F6-40. Já na população VADAC 0063, escolheram-se para seleção os genótipos F4-10, F4-16, F4-23, F4-32, F4-38, F4-41, F4-52, F4-62, F5-10, F5-45, F5-48, F5-54, F5-63 e F5-67 e na população VADAC 0065, os genótipos $9 ; 23 ; 24 ; 40 ; 58 ; 60$ e 71 .

TABELA 1 - Relação das populações de pessegueiro, genealogia e variedade botânica dos indivíduos avaliados quanto à qualidade dos frutos, dentro do programa de melhoramento genético da Estación Experimental de Aula Dei (CSIC), Zaragoza - Espanha.

\begin{tabular}{|c|c|c|c|c|c|}
\hline População & Genitores* & $\begin{array}{c}\text { Pêssego } \\
\left(\mathrm{n}^{\circ}\right)\end{array}$ & $\begin{array}{c}\text { Nectarina } \\
\left(\mathrm{n}^{\mathrm{o}}\right)\end{array}$ & $\begin{array}{c}\text { Peento } \\
\left(\mathrm{n}^{\mathrm{o}}\right)\end{array}$ & Total \\
\hline VADAC 0049 & 'Babygold 9' x 'VAC-9510' & 84 & 0 & 0 & 84 \\
\hline VADAC 0045 & 'Red Top' x 'VAC-9513' & 93 & 0 & 0 & 93 \\
\hline VADAC 0004 & 'Rich Lady’x 'VAC-9511' & 14 & 6 & 0 & 20 \\
\hline VADAC 0050 & 'Babygold 9'x 'Crown Princess' & 65 & 1 & 0 & 66 \\
\hline VADAC 0053 & 'Andross' x 'Rich Lady’ & 38 & 0 & 0 & 38 \\
\hline VADAC 0048 & 'VAC-9512’ x 'VAC-9511' & 18 & 7 & 0 & 25 \\
\hline VADAC 0036 & 'Orion’ x 'VAC-9510' & 11 & 1 & 0 & 12 \\
\hline VADAC 0201 & 'Andross' x 'Calante' & 13 & 2 & 0 & 15 \\
\hline VADAC 9708 & 'Royal Glory’ x ‘VAC-9518' & 7 & 0 & 0 & 07 \\
\hline VADAC 9711 & ‘Royal Glory’x ‘VAC-9519’ & 13 & 0 & 0 & 13 \\
\hline VADAC 0055 & 'VAC-9520’ x 'VAC-9517' & 23 & 8 & 30 & 61 \\
\hline VADAC 0027 & 'Venus' x 'BigTop' & 0 & 58 & 0 & 58 \\
\hline VADAC 0065 & 'O’Henry' x 'VAC-9515' & 27 & 6 & 0 & 33 \\
\hline VADAC 0063 & 'Mercil' x 'VAC-9514' & 59 & 21 & 0 & 80 \\
\hline VADAC 0062 & 'Mercil' x 'VAC-9516' & 45 & & & \\
\hline VADAC 0051 & 'Andross' x 'Crown Princess' & 18 & & & \\
\hline VADAC 0052 & 'Andross' x 'VAC-9511' & 19 & & & \\
\hline Total & & 547 & 110 & 30 & 687 \\
\hline
\end{tabular}

*Alguns genitores utilizados foram identificados com as letras VAC (Variedades Agromillora Catalana) e as populações em fase de seleção foram identificadas com a sigla VADAC (Variedades Aula Dei Agromillora Catalana), seguida de quatro algarismos, dos quais os dois primeiros indicam o ano do cruzamento, e os dois últimos, a combinação de genitores utilizados. 


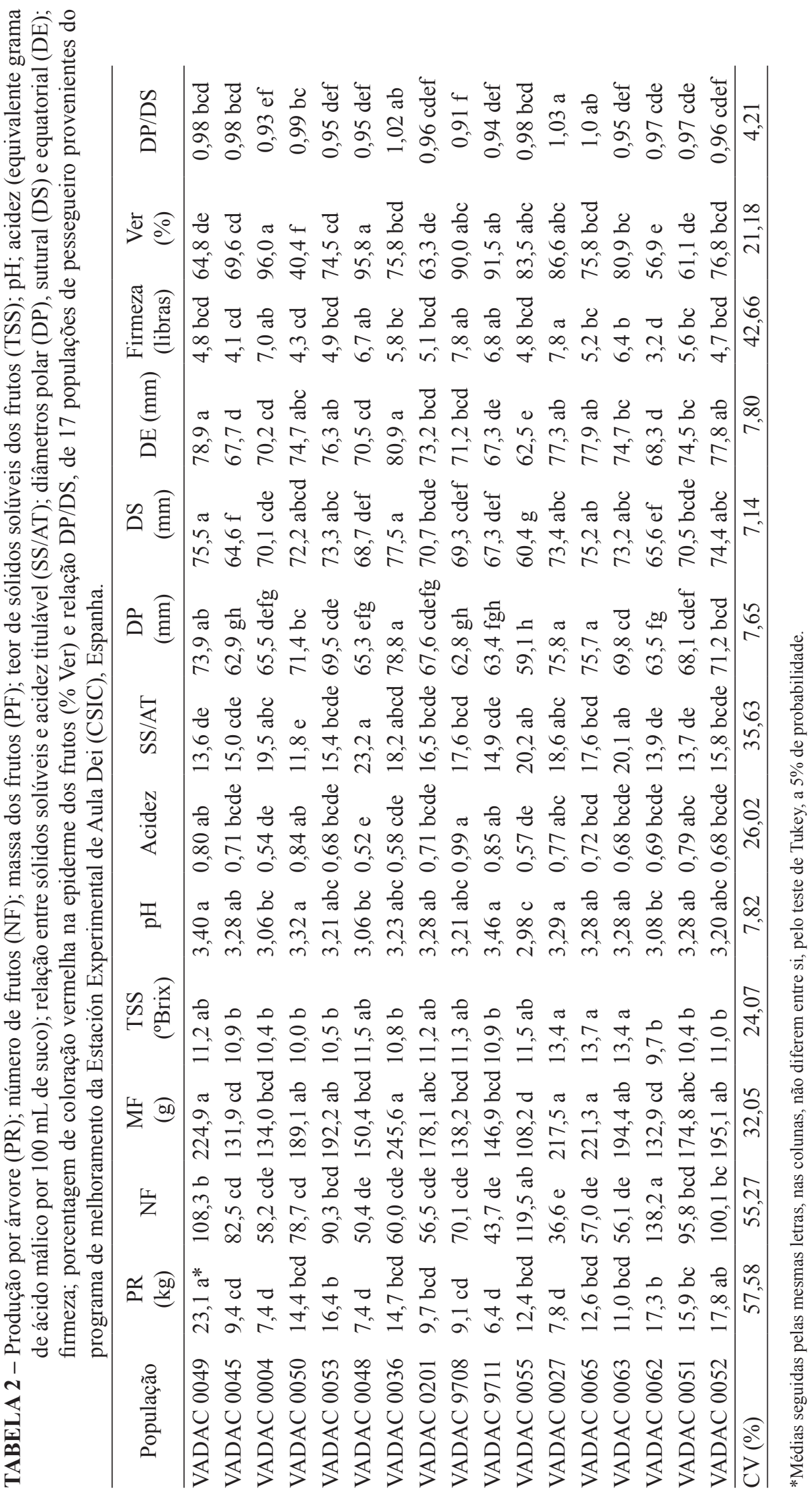


TABELA 3 - Distribuição dos genótipos em cada população de pessegueiro, de acordo com a época de colheita dos frutos.

\begin{tabular}{lccccccc}
\hline População & $\begin{array}{c}16-31 \\
\text { Maio }\end{array}$ & 1-15 Junho & $\begin{array}{c}16-30 \\
\text { Junho }\end{array}$ & $\begin{array}{l}\text { 1-15 Julho } \\
\text { Julho }\end{array}$ & $\begin{array}{c}16-15 \\
\text { Agosto }\end{array}$ & Total \\
\hline VADAC 0049 & - & - & - & 4 & 40 & 40 & 84 \\
VADAC 0045 & 39 & 15 & 14 & 4 & 18 & 3 & 93 \\
VADAC 0004 & - & 1 & 13 & 6 & - & - & 20 \\
VADAC 0050 & - & 29 & 15 & 1 & - & 21 & 66 \\
VADAC 0053 & - & 2 & 7 & 11 & 7 & 11 & 38 \\
VADAC 0048 & - & 9 & 1 & 13 & 2 & & 25 \\
VADAC 0036 & - & 2 & 1 & 3 & 4 & 2 & 12 \\
VADAC 0201 & - & 3 & 7 & - & - & 5 & 15 \\
VADAC 9708 & - & - & 3 & 4 & - & - & 7 \\
VADAC 9711 & - & 1 & 12 & - & - & - & 13 \\
VADAC 0055 & - & 37 & 12 & 11 & - & 1 & 61 \\
VADAC 0027 & - & 3 & 11 & 17 & 3 & 24 & 58 \\
VADAC 0065 & - & - & - & 3 & 23 & 7 & 33 \\
VADAC 0063 & - & - & 1 & 21 & 46 & 12 & 80 \\
VADAC 0062 & - & 2 & 32 & 11 & - & - & 45 \\
VADAC 0051 & - & 2 & 5 & 3 & 5 & 3 & 18 \\
VADAC 0052 & - & 1 & 7 & 4 & 4 & 3 & 19 \\
\hline
\end{tabular}

TABELA 4 - Caracterização dos genótipos das 17 populações de pessegueiro provenientes do programa de melhoramento da Estación Experimental de Aula Dei (CSIC), quanto à textura.

\begin{tabular}{|c|c|c|c|c|c|c|}
\hline \multirow[b]{2}{*}{ População } & \multirow[b]{2}{*}{ Cruzamento $^{1}$} & \multicolumn{2}{|c|}{ Textura } & \multirow{2}{*}{$\begin{array}{c}\text { Proporção } \\
\text { Esperada } \\
\text { Fundente: } \\
\text { Não fundente }\end{array}$} & \multirow[b]{2}{*}{$\chi^{2}$} & \multirow{2}{*}{$\begin{array}{c}\text { Probabilidade } \\
(\%)\end{array}$} \\
\hline & & $\begin{array}{c}\text { Fundente } \\
\text { (\% indivíduos) }\end{array}$ & $\begin{array}{l}\text { Não fundente } \\
\text { (\% indivíduos) }\end{array}$ & & & \\
\hline VADAC 0049 & $? \times ?$ & 59,52 & 40,48 & $1: 1$ & $3,05 \mathrm{~ns}$ & 8,09 \\
\hline VADAC 0045 & $\mathrm{~F} x ?$ & 53,76 & 46,24 & $1: 1$ & $0,52 \mathrm{~ns}$ & 46,79 \\
\hline VADAC 0004 & $\mathrm{~F} \times \mathrm{F}$ & 30,00 & 70,00 & $3: 1$ & $21,60 * *$ & 0,00 \\
\hline VADAC 0050 & $? \times \mathrm{NF}$ & 45,76 & 54,24 & $1: 1$ & $0,42 \mathrm{~ns}$ & 51,51 \\
\hline VADAC 0053 & $N F \times F$ & 60,53 & 39,47 & $1: 1$ & $1,68 \mathrm{~ns}$ & 19,44 \\
\hline VADAC 0048 & $\mathrm{~F} \times \mathrm{F}$ & 44,00 & 56,00 & $3: 1$ & $12,81 * *$ & 0,03 \\
\hline VADAC 0036 & $? \times ?$ & 58,33 & 41,67 & $1: 1$ & $0,33 \mathrm{~ns}$ & 56,37 \\
\hline VADAC 0201 & NF $x$ NF & 53,33 & 46,67 & $0: 1$ & $* * *$ & \\
\hline VADAC 9708 & $\mathrm{Fx} ?$ & 71,43 & 28,57 & $3: 1$ & $0,05 \mathrm{~ns}$ & 82,73 \\
\hline VADAC 9711 & $\mathrm{Fx} ?$ & 76,92 & 23,08 & $3: 1$ & $0,03 \mathrm{~ns}$ & 87,28 \\
\hline VADAC 0055 & $? \times ?$ & 41,94 & 58,06 & $1: 1$ & $1,33 \mathrm{~ns}$ & 24,92 \\
\hline VADAC 0027 & NF $x$ F & 43,10 & 56,90 & $1: 1$ & $1,10 \mathrm{~ns}$ & 29,35 \\
\hline VADAC 0065 & $\mathrm{Fx} ?$ & 54,55 & 45,45 & $1: 1$ & $0,27 \mathrm{~ns}$ & 60,15 \\
\hline VADAC 0063 & $\mathrm{Fx} ?$ & 50,00 & 50,00 & $1: 1$ & $0,00 \mathrm{~ns}$ & 100,00 \\
\hline VADAC 0062 & $\mathrm{~F} x ?$ & 57,78 & 42,22 & $1: 1$ & $1,09 \mathrm{~ns}$ & 29,67 \\
\hline VADAC 0051 & NF $x$ NF & 66,67 & 33,33 & $0: 1$ & $* * *$ & \\
\hline VADAC 0052 & $N F \times F$ & 57,89 & 42,11 & $1: 1$ & $0,47 \mathrm{~ns}$ & 49,13 \\
\hline
\end{tabular}

${ }^{1}(\mathrm{~F})$ textura fundente; (NF) textura não fundente; (?) sem informação sobre textura. $\mathrm{ns}, *$ * **. Não significativo, significativo a $\mathrm{P}=0,05$ e $\mathrm{P}=0,01$, respectivamente.

$* * *$ - Teste $\chi^{2}$ não aplicável. 


\section{CONCLUSÕES}

1-Recomenda-se a incorporação no programa de melhoramento genético do pessegueiro da Universidade Federal de Viçosa de pólen do genitor 'Crown Princess', visando a obter frutos de boa qualidade e com textura não fundente.

2-Sugerem-se, para a incorporação no programa da UFV, 46 genótipos superiores selecionados quanto à qualidade dos frutos, das populações em fase de seleção VADAC 0027, VADAC 0050, VADAC 0063 e VADAC 0065.

\section{AGRADECIMENTOS}

À equipe espanhola da Estación Experimental de Aula Dei, pela acolhida e auxílio na execução dos trabalhos. À Coordenação de Aperfeiçoamento de Pessoal de Nível Superior (CAPES), pelo apoio financeiro e pela concessão da bolsa para a realização do Doutorado-Sandwich.

\section{REFERÊNCIAS}

ALBUQUERQUE, A.S.; BRUCKNER, C.H.; CRUZ, C.D.; SALOMÃO, L.C.C. Avaliação de cultivares de pêssego e nectarina em Araponga, Minas Gerais. Revista Ceres, Viçosa, MG, v.47, n.272, p.401-410, 2000.

BADENES, M.L.; WERNER, D.J.; MARTINEZCALVO, J.; LORENTE, M.; LLACER, G. An overview of the peach industry of Spain. Fruit Varieties Journal, University Park, PA, v.52, n.1, p.11-17, 1998.

BARBOSA, W.; OJIMA, M.; DALL'ORTO, F.A.C. Comportamento do pessegueiro 'Douradão' em Itupeva. Scientia Agrícola, Piracicaba, v.56, n.4, p.1261-1265, 1999.

BIASI, L.A.; ZANETTE, F.; PETRI, J.L.; MARODIN, G.A.B. Cultivares de fruteiras de caroço. In: MONTEIRO, L.B.; DE MIO, L.L.M.; SERRAT, B.M.; MOTTA, A.C.; CUQUEL, F.L. Fruteiras de caroço: uma visão ecológica. Curitiba: UFPR, 2004. p.5-19.
BOUHADIDA, M.; CASAS, A.M.; MORENO, M.A.; GOGORCENA, Y. Molecular characterization of Miraflores peach variety and relatives using SSRs. Scientia Horticulturae, Amsterdam, v.111, p.140-145, 2007.

BYRNE, D.H.; BACON, T.A. Founding clones of low-chill fresh market peach germoplasm. Fruit Varieties Journal, University Park, PA, v.53, n.3, p.162-171, 1999.

CAILlAVET, H.; SOUTY, J. Monographie des principales variétés de pêches. ITEA, v.37, p.1826, 1950.

CANTILLANO, R.F.F.; SACHS, S. Colheita, classificação, embalagem e armazenagem. EMBRAPA/ Centro Nacional de Pesquisa em Fruteiras de Clima Temperado. A cultura do pessegueiro. Pelotas: EMBRAPA/CNPFT, 1984. p.113-119.

CHITARRA, M.I.F.; CHITARRA, A.B. Pós-colheita de frutas e hortaliças: glossário. Lavras: Editora UFLA. 2006. 256 p.

CLARETON, M. Peach and nectarine production in France: Trends, consumption, and perpectives. In: PRUNUS BREEDERS MEETING, 2000., Pelotas. Summaries... Pelotas: Embrapa Clima Temperado, 2000. p. 83-91. (Documentos, 75).

\section{CRUZ, C.D. Programa GENES - versão Windo-} ws: aplicativo computacional em genética e estatística. Viçosa: Ed. UFV, 2001. 648 p.

DIRLEWANGER, E.; MOING, A.; ROTHAN, C.; SVANELLA, L.; PRONIER, V.; GUYE, A.; PLOMION, C.; MONET, R. Mapping QTLs controlling fruit quality in peach (Prunus persica (L.) Batsch). Theoretical Applied Genetics, Berlin, v.98, p.18 31, 1999.

EMBRAPA. Centro Nacional de Pesquisa de Fruteiras de Clima Temperado. Pelotas. A cultura do Pessegueiro. Pelotas, 1984. 156 p. (Circular Técnica, 10).

FRECON, J.L.; BELDING, R.L.; LOKAJ, G. Evaluation of white-fleshed peach and nectarine varieties in New Jersey. Acta Horticulturae, Wageningen, n.592, p.467-477, 2002. 
GIOVANNINI, D.; LIVERANI, M.M.; BRANDI, F. Breeding strategies to improve peach fruit quality. Acta Horticulturae, Wageningen, n.713, p.107112, 2006.

KADER, A.A.; MITCHELL, F.G. Maturity and quality. In: LARUE, J.H.; JOHNSON, R.S. (Ed.). Peaches, plums and nectarines: growing and handling for fresh market. Davis: University of California, 1989. p.191-196.

LEONARD, S.; LUSH, B.S.; HINREINER, E. Flavor evaluation of canned cling peaches. Food Technology, Chicago, v.2, p.480 - 485, 1953.

RASEIRA, M.C.B.; NAKASU, B.H. EmbrapaCPACT prunus breeding program. In: PRUNUS BREEDERS MEETING, 2000, Pelotas. Summaries.... Pelotas: Embrapa Clima Temperado, 2000. p. 73-77. (Documentos, 75).

RASEIRA, M.C.B.; NAKASU, B.H. Peach breeding program in southern Brazil. Acta Horticulturae, Wageningen, n.713, p.93-97, 2006.

RASEIRA, M.C.B.; NAKASU, B.H.; SANTOS, A.M.; FORTES, J.F.; MARTINS, O.M.; RASEIRA, A.; BARNARDI, J. The CNPFT/EMBRAPA fruit breeding program in Brazil. HortScience, Alexandria, v.27, p.1154-1157, 1992.
SOUZA, V.A.B.; BYRNE, D.H.; TAYLOR, J.F. Heritability, genetic and phenotypic correlations, and predicted selection response of quantitative traits in peach: II. An analysis of several fruit traits. HortScience, Alexandria, v.123, n.4, p.604-611, 1998.

SOUZA, V.A.B.; BYRNE, D.H.; TAYLOR, J.F. Predicted breeding values for nine plant and fruit characteristics of 28 peach genotypes. HortScience, Alexandria, v.125, n.4, p.460 - 465, 2000.

TREVISAN, R. Avaliação da qualidade de pêssegos cv. Maciel, em função do manejo fitotécnico. 2003. 105 f. Tese (Doutorado em Agronomia) - Departamento de Fitotecnia, Universidade Federal de Pelotas, Pelotas, 2003.

WATADA, A.E.; ABBOTT, J.A.; FINNEY JUNIOR, E.E. Firmess of peach measured nondestructively. Journal of the American Society for Horticultural Science, Alexandria, v.101, n.4, p.404-406, 1976. 